\title{
Biochar applications influence soil physical and chemical properties, microbial diversity, and crop productivity: a meta-analysis
}

\author{
Hardeep Singh ${ }^{1,2}$ (D) $\cdot$ Brian K. Northup ${ }^{2} \cdot$ Charles W. Rice $^{1} \cdot$ P. V. Vara Prasad ${ }^{1}$
}

Received: 23 August 2021 / Accepted: 17 January 2022

(c) The Author(s) 2022

\begin{abstract}
Biochar is a widely known soil amendment. Here we synthesize the available information on influence of biochar application on different soil properties and crop productivity using meta-analysis. Global data on influence of biochar applications on different soil physical, chemical, microbial properties, and crop productivity were extracted from literature and statistically analyzed. Based on selection criteria, 59 studies from the literature published between 2012 and 2021 were selected for the meta-analysis. Correlations were developed between effect size of biochar application on different soil properties and crop productivity. Application of biochar increased soil pH, cation exchange capacity, and organic carbon by 46\%, 20\%, and $27 \%$, respectively, with greater effects in coarse and fine-textured soils. Effects on chemical properties were variable among biochar prepared from different feedstocks. Among physical properties, biochar application reduced bulk densities by $29 \%$ and increased porosity by $59 \%$. Biochar prepared at higher pyrolytic temperatures $\left(>500{ }^{\circ} \mathrm{C}\right)$ improved bulk density and porosity to greater extents $\left(31 \%\right.$ and $66 \%$, respectively). Biochar prepared at lower pyrolytic temperatures $\left(<500{ }^{\circ} \mathrm{C}\right)$ had a greater effect on microbial diversity (both bacterial and fungal), with more diverse bacterial populations in medium and coarse textured soils, while fungal diversity increased in fine textured soils. Biochar applications increased crop productivity only in fine and coarse textured soil. The effect size of biochar application on crop productivity was correlated with responses to physical properties of soils. The meta-analysis highlighted the need to conduct long-term field experiments to provide better explanations for changes in biochar properties as it undergoes aging, its longer-term effects on soil properties, and timing of re-application of different biochars.
\end{abstract}

\section{Highlights}

- Meta-analysis was conducted to assess overall effect of biochar application to soil.

- Biochar application increased soil pH, CEC, and organic carbon with greater effects in controlled environment studies.
- Microbial diversity was increased with biochar application but was negatively affected at higher rates.

Keywords Biochar $\cdot$ Crop productivity $\cdot$ Microbial diversity $\cdot$ Soil physical properties $\cdot$ Soil chemical properties

Hardeep Singh

hardeep@ksu.edu

$\triangle$ P. V. Vara Prasad vara@ksu.edu

1 Department of Agronomy, Kansas State University, 2002 Throckmorton Plant Sciences Center, 1712 Claflin Road, Manhattan, KS 66506, USA

2 United States Department of Agriculture - Agricultural Research Service, Grazinglands Research Laboratory, El-Reno, OK 73036, USA

\section{Introduction}

Agricultural productivity is continually limited by progressive declines in soil condition and poor nutrient use efficiencies, resulting in food insecurity (Jones et al. 2013). Problems such as climate change, increasing growth of the human population, and urbanization place increased pressure on agricultural systems, which aggravates these problems (Lal 2009). Therefore, the design and function of 
agroecosystems need to be reconsidered, to resolve the wide array of problems affecting agricultural production, including disconnects in nutrient supply, demand, and recycling, and water use (Lal 2013). One potential solution could be recycling organic nutrients back to soil, to help sustain soil organic matter, which typically results in improvements in soil physical and chemical properties (Girmay et al. 2008). Different sources of organic matter can be added to soil, including crop residues, animal waste, household waste, and industrial waste (Ali et al. 2011; Quilty and Cattle 2011). However, the selection of organic material to apply is critical, since some sources may have negative effects on soils, depending upon the quality of organic material or the presence of contaminants (Jones and Healey 2010).

Biochar is one potential amendment to improve soil properties. It is used as a soil amendment for its well-researched benefits, such as increasing soil fertility and immobilizing and transforming heavy metals and contaminants in agricultural soils (Zhu et al. 2017). Generally, biochar is referred to as "biomass derived black carbon" or "charcoal" with the potential to act as a sink for carbon over an extended period (Lehmann et al. 2006). It is believed to have been first used by the pre-Columbian indigenous people of the Amazon region in the ages 500 to 9000 years BP (Solomon et al. 2007), as part of a series of soil amendments that produced 'terra preta', a more nutrient-rich and high $\mathrm{pH}$ agricultural soil than the existing acidic and infertile soils of the region (Lehman et al. 2007).

Biochar is defined as a solid and stable, carbon-rich material formed by heating of bio-based or organic materials in the absence of oxygen (pyrolysis) (Chan et al. 2008; Woolf et al. 2010). Some researchers have referred to it as "agrichar", or charcoal for agricultural use, due to recent interest in using biochar in developing sustainable forms of soil management and issues related to climate change (Abewa et al. 2014; Laine 2012; Yao et al. 2012). Biochar can be generated from a range of different feedstocks, including organic and industrial wastes (e.g., sludges, manure), plant-based materials (e.g., leaves, husks, seeds, cobs), and wood-based products (e.g., woodchips, wood pellets, tree bark). Biochar can also be produced at different pyrolytic temperatures and durations of pyrolysis. The combination of feedstock type and pyrolysis conditions allows the production of biochars with a range of physical and chemical properties (Mukherjee and Zimmerman 2013).

Various studies reported improvements in soil properties beyond carbon sequestration that were related to biochar application. However, the effects of biochar applications on soil properties vary as a function of feedstock source and temperature used in pyrolysis (Mukherjee and Zimmerman 2013). In general, several studies reported some chemical properties of soils, such as soil $\mathrm{pH}$, cation exchange capacity (CEC), organic carbon (OC), electrical conductivity
(EC), and extractable nutrients increased in response to different types of biochar (Wang et al. 2013). Physical properties of soils, such as bulk density and different aspects of soil structure also improved in response to amendments including biochar (Blanco-Canqui 2017). Additionally, biochar amendments could increase water holding capacities of soil (Razzaghi et al. 2020), and result in changes in composition, abundance, and activities of microbial communities in soils (Lehmann et al. 2011; Chan et al. 2008) by providing environments with ample aeration, water, and nutrients (Ameloot et al. 2013; McCormack et al. 2013). As a consequence of such changes in microbial populations, key soil processes such as the formation of OC, carbon mineralization, and nutrient transformations could be altered by the addition of biochar to soil (Ullah et al. 2020).

The services provided to crop growth and development by the soil are directly or indirectly influenced by changes in soil physical and chemical properties (Blanco-Canqui 2017). For example, soil physical and hydraulic properties influence macro- and microscale processes, including root growth, aeration, compaction, water and nutrient uptake, surface and subsurface water pollution, erosion, and fluxes in water, heat, and gasses. Additionally, biochar was reported to improve crop growth and development in acidic soils by increasing soil pH (Syuhada et al. 2016). While biochar applications hold promise for improving many soil properties, results from different studies were inconsistent (Atkinson 2018). The effects of biochar on microbial diversity and composition were also variable. Drivers of inconsistencies in responses are various, including heterogeneity among experiments related to; soil types, rates of biochar application (ranging from 5 to $150 \mathrm{t} \mathrm{ha}^{-1}$ ), properties of biochar as a function of feedstock and pyrolytic conditions, and type of experiment (laboratory vs. greenhouse vs. field).

Inconsistencies in responses indicate a need for a metaanalysis from existing experimental studies to: (i) establish the effect of biochar application on soil physical and chemical properties and microbial diversity; (ii) develop correlations between effects on soil properties and crop productivity; and (iii) identify research gaps. Though there have been syntheses and meta-analyses conducted in the past, they primarily analyzed limited biochar application types on either soil physical, chemical, soil water retention or microbial properties independently. Therefore, we considered how biochar affected soil physical and chemical properties, microbial diversity helps in increasing crop productivity and developing correlations between factors, thereby increasing the sustainability of agricultural systems. The primary focus of this meta-analysis was how biochar application to soils alters soil physical and chemical properties, and microbial diversity, which are important to crop growth and productivity. The meta-analysis expands on the previous studies on relationships between biochar, soil physical and chemical 
properties and microbial diversity. In addition, our analysis scrutinizes relationships to define impacts of biochar on soil physical properties (such as porosity and bulk density), chemical properties (soil pH, EC, CEC, and OC), and microbial diversity (bacterial and fungal).

\section{Methods}

\subsection{Data sources}

An extensive literature search was performed using different search engines, including Google Scholar, Web of Sciences, ScienceDirect, and Scopus, to identify data for the metaanalysis. The search terms included different combinations (including 'and', 'or') of the words: "biochar", "char", "soil physical properties", "soil chemical properties", "microbial diversity", "Shannon index", "crop productivity", “crop production", "crop yield". Additionally, the reference lists of selected papers were also used to ensure the literature search included comprehensive lists of studies related to search topics.

\subsection{Article screening and data collection}

After completion of searches, the articles were screened based on a series of pre-defined criteria: (i) published in peer reviewed journal; (ii) availability of feedstock used for biochar preparation and information on rates of biochar application; (iii) published in English; (iv) availability of soil information (soil textural class); (v) data available for at least 2 target variables; (vi) studies include replicated biochar treatments and controls (no biochar); (vii) measures of variance in responses are provided. In cases where variance was not provided, corresponding authors were contacted to obtain the information. Studies having this information were included in the meta-analysis, while those without requisite information were excluded. Of the total studies examined, 59 met the inclusion criteria, and provided pairwise comparisons of different biochar treatments vs. controls (Supplementary Table S1). The publication date for the articles to be considered for inclusion ranged from 2012 to 2021 .

Categorical information related to biochar (rate applied, type of feedstock, pyrolytic temperature), soil (texture), and experimental setup (field, greenhouse, or laboratory) was collected from manuscripts and recorded as auxiliary variables. The target variables included bulk density of soils, porosity, $\mathrm{pH}, \mathrm{EC}, \mathrm{CEC}, \mathrm{OC}$, microbial diversity (fungal and bacterial Shannon indices), and crop yield. The data for target variables presented in the form of tables were collected directly from the articles. However, if the data were presented in graphical form, they were collected using Web Plot Digitizer (Rohatgi 2016). For each study, both the control and treatment means were recorded. Additionally, standard deviations were calculated for the articles where error bars represented the standard errors. This resulted in: 100 datasets for bulk density, 70 datasets for soil porosity, 157 datasets for soil $\mathrm{pH}, 83$ datasets for soil EC, 73 datasets for soil CEC, 105 datasets for soil OC, 110 datasets for crop yield, 36 datasets for Shannon index defining fungal diversity, and 85 datasets for Shannon index defining bacterial diversity.

\subsection{Data grouping}

To allow cross-comparisons between studies, auxiliary variables were grouped based on information published in peer-reviewed articles. The rates of biochar application were grouped as; low (1-39 t ha-1), medium (40-80 $\left.\mathrm{tha}^{-1}\right)$, and high $\left(>80 \mathrm{tha}^{-1}\right)$ rates. The biochar feedstocks were grouped as manures (swine, cattle, and chicken manure); wood (oak, pine, willow, acacia bark and unidentified wood mixtures), herbaceous materials (green waste, red gram stalks, maize stover, straws, switchgrass); and lignocellulosic wastes (including rice husks, rice hulls, shells of nuts, coffee husks, corn cobs, vineyard pruning, pine sawdust). The pyrolytic temperatures used for biochar preparation were grouped as low $\left(\leq 500{ }^{\circ} \mathrm{C}\right)$ and high $\left(>500{ }^{\circ} \mathrm{C}\right)$. Set up of experiments was grouped into field, greenhouse, and laboratory experiments. The studies were also grouped based on soil texture, with fine-textured, medium-textured, and coarse-textured soils, as defined by Cornell Soil Health Laboratory recommendations (Soil Texture - Cornell Soil Health Laboratory). The coarse-textured group included sands, loamy sands, and sandy loams, while the medium textured group was comprised of loams, silt loams, silts, and sandy clay loams. The fine-textured group was comprised of clay loams, silty clay loams, sandy clays, silty clays, and clays. A concise summary of the groupings and the studies is presented in Supplementary table 2.

Based on screening, 59 published studies were included in the meta-analysis (Supplementary Table 1). The feedstock used for preparing biochar included wood, crop residues, straw, peanut hulls, pine chips, acacia bark, animal manure, and chicken manure. The temperature of pyrolysis used for preparing biochar in the different studies ranged from 200 to $900{ }^{\circ} \mathrm{C}$ with a median of $500{ }^{\circ} \mathrm{C}$ (Fig. 1). In the selected studies, the duration of pyrolysis ranged from less than one minute (3 s) to $4300 \mathrm{~min}$, with a median of $60 \mathrm{~min}$ (Fig. 1).

Most of the studies in the meta-analysis were conducted on sandy loam soils, followed by clay loams and loams. Sandy clay and sandy clay loams were the least-studied textural classes. According to textural groupings of soils, $44 \%$, $39 \%$, and $17 \%$ of studies were conducted, respectively, on medium-textured (loams, silt loams, silts, and sandy clay loams), coarse-textured (sands, loamy sands, and sandy 


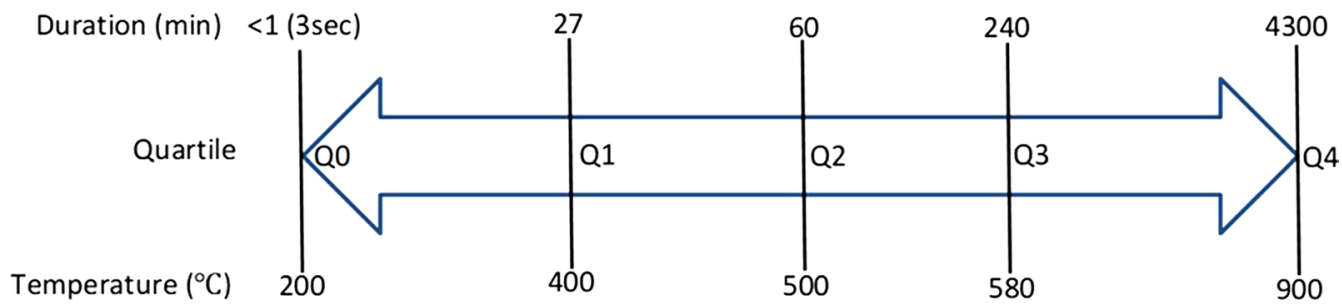

Fig. 1 Distribution of pyrolysis duration and temperatures for the selected studies; Q0, Q1, Q2, Q3, and Q4 correspond to the minimum, 25\%, $50 \%$, and $75 \%$ quartiles, and the maximum value, respectively

loams), and fine-textured (clay loams, silty clay loams, sandy clays, silty clays, and clays) soils.

\subsection{Meta-analysis}

The effects of biochar additions on soil physical and chemical properties, microbial properties, and crop productivity were quantified. The effect size of biochar applications was calculated for each study to standardize the results across all selected studies. This allowed pooling of quantitative statistical information, and statistical comparisons between effects from the range of studies that reported results based on different experimental variables. The effect size was calculated using the computer software package Comprehensive Meta-Analysis (CMA) (Hedges et al. 2005). The standardized mean difference metric "Hedge's g" was used for computing the effect size (Eqs. (1), (2), and (3); Hedges and Olkin 2014). "Hedge's g" was selected rather than "Cohen's d" because it was less biased by small sample sizes (Hedges and Olkin 2014), which was the case for most studies included in the meta-analysis.

Hedgesg $=J \frac{\overline{X_{t}}-\overline{X_{c}}}{S_{\text {within }}}$

$S_{\text {within }}=\sqrt{\frac{\left(n_{T}-1\right) S_{T}^{2}+\left(n_{C}-1\right) S_{C}^{2}}{n_{T}+n_{c}-2}}$

$J=1-\frac{3}{4\left(n_{T}+n_{c}-2\right)-1}$

where: $\bar{X}_{t}$ and $\overline{X_{c}}$ represent the mean for biochar and control treatments, respectively; $S_{\text {within }}$ represents standard deviation between treatments; $J$ represents standard sample size; $n_{T}$ and $n_{C}$ represent the sample size of the biochar and control treatments, respectively; and $S_{T}$ and $S_{c}$ represent standard deviation for the biochar and control treatments, respectively. Hedge's $g$ is based on the number of standard deviations in difference that exists between two groups; (Hedge's $\mathrm{g}=1$ indicates two groups differ by 1 standard deviation, etc.). A commonly used criteria for interpreting Hedge's $\mathrm{g}$ is to refer to sizes of effects as small $(\mathrm{g}=0.2)$, medium $(\mathrm{g}=0.5)$, and large $(\mathrm{g}=0.8)$ (Lakens 2013).

The overall effect of biochar on different soil properties, microbial diversity, and crop production was estimated by a random-effects model. The random effects approach was used since the various studies included in the meta-analysis were not expected to have effect sizes that were common due to variations in the experimental conditions and procedures used in the different studies (Borenstein et al. 2011). Additionally, sampling error was not the only source of variation expected to influence the effect size among the various studies (Borenstein et al. 2011).

\subsection{Graph presentations}

Forest plots were prepared to show effect sizes calculated for each study with Sigma Plot 14.5. Each point represents the mean effect size calculated by Hedge's g, and the lines represent the $95 \%$ confidence interval (CI) for each group. Numbers on the right side of the forest plot represent the number of replications included in groupings. The overall effect of biochar on a specific parameter was represented by the dotted line in the graph. Two groups were considered to be significantly different if $95 \%$ CI for effect sizes of both groups did not overlap. Additionally, groups were considered significantly different from controls if CI for overall effect sizes did not include zero.

\section{Results}

\subsection{Influence on soil chemical properties}

Variations in chemical properties (soil pH, EC, CEC, and OC) of soils in response to biochar addition grouped by different categories (type of study, feedstock type, soil texture, pyrolysis temperature, and application rate) are presented in Fig. 2. 

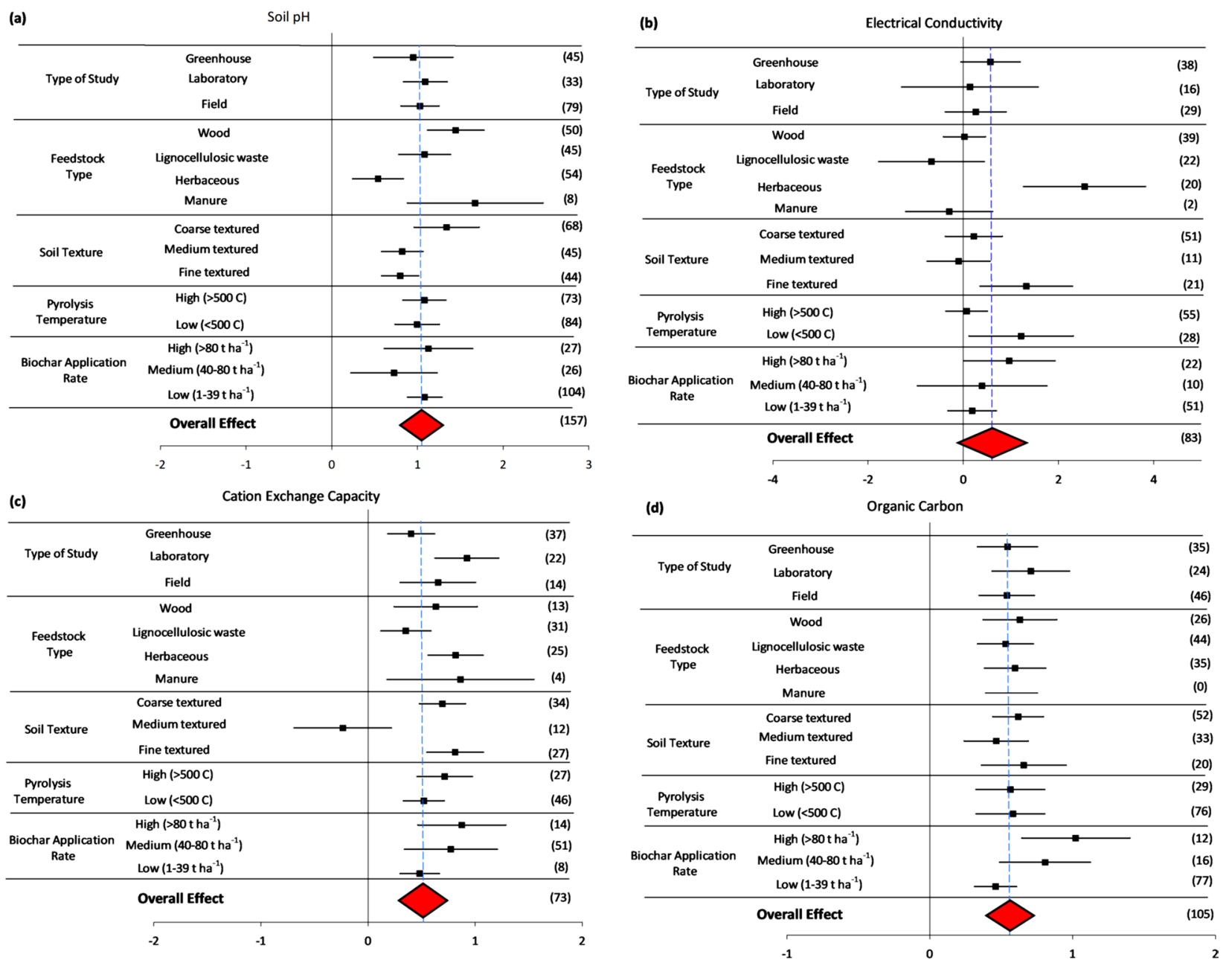

Fig. 2 Forest plots showing mean changes in chemical properties of soils for different categories grouped by type of biochar, feedstock type, soil texture, pyrolysis temperature, and application rate; a soil $\mathrm{pH}$, b electrical conductivity, c cation exchange capacity, and d organic carbon due to biochar addition to soil. Points show treatment

effect for a given group and bars represent $95 \%$ confidence interval for specific categories; blue tick lines show overall effects (grand mean), and numbers at right are total numbers of replicates (n) from the combined studies

\subsubsection{Soil pH}

In general, application of biochar significantly $(P<0.001)$ increased soil $\mathrm{pH}$ compared to the control (Fig. 2a). Soil pH increased significantly $(P<0.05)$ in all study settings including field, laboratory, and greenhouse studies. Similarly, soil $\mathrm{pH}(P<0.05)$ significantly increased in response to biochar regardless of feedstock. The increase in soil $\mathrm{pH}$ was more pronounced for biochars prepared from wood (58\%), lignocellulosic waste $(47 \%)$, and manures (64\%) compared to biochars prepared from herbaceous feedstocks (26\%). Additionally, the increase in soil $\mathrm{pH}$ was significant $(P<0.05)$ for all soil textures but was most pronounced in coarse-textured soils (55\%). The increase in soil $\mathrm{pH}$ in coarse-textured soils was significantly $(P<0.05)$ greater than in fine-textured soils. Biochars prepared at both high and low pyrolytic

temperatures resulted in a significant $(P<0.05)$ increase in soil $\mathrm{pH}$ compared to the control. However, the effect size was not significantly different among temperature groups. The significant $(P<0.05)$ increase in soil $\mathrm{pH}$ compared to controls occurred for all rates of biochar application. However, the soil $\mathrm{pH}$ increase with biochar application was more pronounced for higher (49\%) and lower (47\%) rates of application than medium (34\%) rates.

\subsubsection{Soil EC}

Overall, changes in soil EC from biochar applications were not significant, as the effect sizes of biochar applications included zero in the CI (Fig. 2b). There was no significant increase in soil EC in different experimental settings (field, greenhouse, or laboratory). Wood, lignocellulosic waste, 
and manure-derived feedstocks did not significantly increase soil EC, while biochar prepared from herbaceous feedstocks significantly $(P<0.05)$ increased soil EC compared to the control by $78 \%$. Biochar applications significantly $(P<0.05)$ increased soil EC compared to the control for fine-textured soils $(55 \%)$, but not in the other textural groups. Biochar prepared at lower temperatures significantly $(P<0.05)$ increased soil EC compared to the control (51\%), while biochar prepared at higher temperatures did not increase soil EC. An increase in soil EC was only significant $(P<0.05)$ at higher rates of application $\left(>80 \mathrm{t} \mathrm{ha}^{-1}\right)$, which was $43 \%$ greater than the control.

\subsubsection{Soil CEC}

Biochar applications significantly $(P<0.0001)$ increased soil CEC compared to the control (Fig. 2c). All study settings (greenhouse, laboratory, and field) significantly $(P<0.05)$ increased soil CEC with biochar applications compared to the control, with a more pronounced increase $(41 \%)$ in the laboratory experiments followed by field (31\%) and pot studies (19\%). Biochar applications significantly increased $(P<0.05)$ soil CEC when applied to coarse or fine-textured soils (37\%) but no effects were recorded in medium-textured soils. Biochars prepared at both high and low pyrolytic temperatures significantly increased $(P<0.05)$ soil CEC compared to the control, with more pronounced increases (33\%) for biochar prepared at higher temperatures. All rates of biochar application significantly increased $(P<0.05)$ soil CEC compared to the control. The effect size of application rates on soil CEC increased with increasing application rate (higher $>$ medium $>$ lower). The percent increase in soil CEC resulting from biochar applications was 45\%, 37\% and 22\% under high, medium and lower application rates, respectively. There was no significant difference in effect sizes on soil CEC among biochars prepared from different feedstocks (wood, ligno-cellulosic waste, herbaceous, and manures).

\subsubsection{Soil OC}

Biochar applications significantly $(P<0.0001)$ increased soil OC compared to control treatments, which was represented by an overall effect significantly different than zero (Fig. 2d). Soil OC was significantly $(P<0.05)$ increased compared to the control for all study settings (greenhouse, laboratory, and field), with more pronounced increases (33\%) for the laboratory studies. However, these responses were not significantly different from responses observed under field and greenhouse settings. Similarly, biochars prepared from all feedstocks significantly $(P<0.05)$ increased soil OC compared to the control but was not significantly different among the different feedstocks used in biochar production. The increase in soil OC was greatest (30\%) under biochar prepared from wood feedstock while increases from biochars prepared using herbaceous and lignocellulosic waste was $28 \%$ and $25 \%$, respectively. Biochar application significantly $(P<0.05)$ increased soil OC for all texture groups of soils compared to the control, while differences among soil textures were not significant. The increase in soil $\mathrm{OC}$ as a result of biochar application was greatest $(31 \%)$ when applied to fine textured soils while increases in for coarse and medium textured soils were $29 \%$ and $22 \%$, respectively. Biochars prepared under both high and low pyrolytic temperatures significantly $(P<0.05)$ increased soil OC compared to the control. Similarly, biochar applied at all rates significantly $(P<0.05)$ increased soil OC compared to the control. Amounts of soil OC increased with increasing rates of biochar application were $45 \%, 37 \%$ and $22 \%$ increases for high, medium, and low application rates, respectively.

\subsection{Influence on soil physical properties}

Variations in physical properties of soil (bulk density and porosity) in response to biochar additions grouped by different categories (type of study, feedstock type, soil texture, pyrolysis temperature, and biochar application) are presented in Fig. 3.

\subsubsection{Bulk density}

Biochar application significantly $(P<0.0001)$ reduced bulk density of soils compared to controls (Fig. 3a). Bulk density declined significantly $(P<0.05)$ compared to controls for all three study settings. However, the decrease was more pronounced $(62 \%)$ and significantly $(P<0.05)$ greater in greenhouse studies than in laboratory $(30 \%)$ and field studies (23\%). All biochar feedstock types significantly $(P<0.05)$ decreased bulk density compared to the control. However, there was no significant difference among the different feedstocks. The present study was unable to include studies testing effects of biochar produced from animal manures on bulk density due to limited data. Bulk density was significantly $(P<0.05)$ reduced in coarse $(36 \%)$ and fine-textured soils (19\%) with biochar applications compared to controls, while the decrease was less pronounced for medium-textured soils (14\%). Biochars prepared at both high and low pyrolytic temperatures significantly decreased $(P<0.05)$ bulk density compared to the control by $31 \%$ and $28 \%$, respectively. Biochar application at all rates significantly $(P<0.05)$ decreased bulk density compared to the control. However, the decreases in bulk density were significantly greater for the higher (56\%) and medium (45\%) application rates than lower (18\%) application rates. 


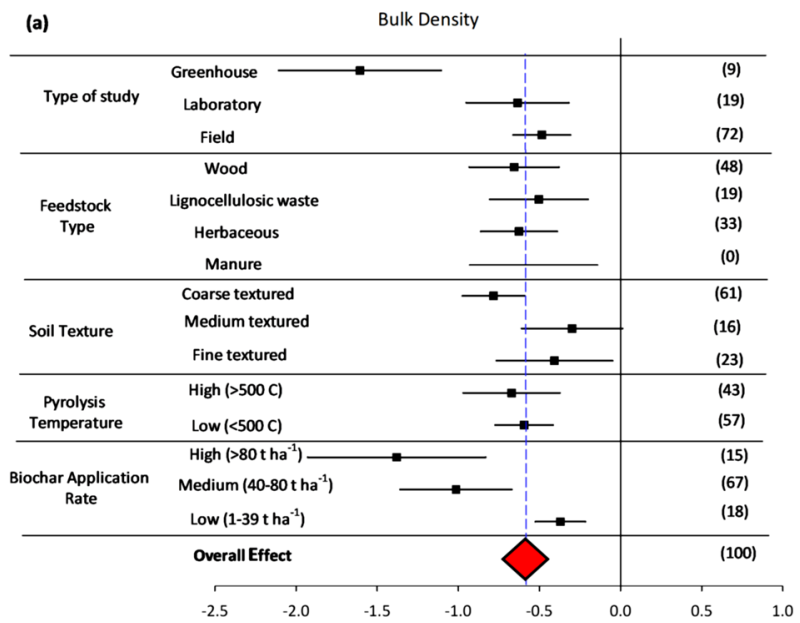

Fig. 3 Forest plots showing mean changes in physical properties due to biochar addition to soil for different categories grouped by type of biochar, feedstock type, soil texture, pyrolysis temperature, and application rate; a bulk density; and $\mathbf{b}$ porosity. Points show treatment

\subsubsection{Soil porosity}

Due to the inverse relationship between bulk density and soil porosity, soil porosity significantly $(P<0.05)$ increased with biochar applications, compared to the controls (Fig. 3b). Soil porosity significantly $(P<0.05)$ increased compared to control treatments for all three study settings. The increase in soil porosity was more pronounced in laboratory studies $(71 \%)$, but responses were not significantly different from those recorded in greenhouse (62\%) and field studies (54\%). Similar magnitudes of increase in soil porosity were observed for all feedstock types (59\%). Biochar application significantly $(P<0.05)$ increased soil porosity for all soil textures, compared to the control. However, the effect was more pronounced for coarse-textured soils (65\%), as was recorded for bulk density. Biochar prepared under both high and low pyrolytic temperatures significantly increased $(P<0.05)$ soil porosity compared to controls; the effect was more pronounced with biochar prepared at higher temperatures $(66 \%)$. All rates of biochar application significantly increased $(P<0.05)$ soil porosity. The effect sizes were greatest for medium application rates $(78 \%)$, and significantly $(P<0.05)$ different from lower rates $(52 \%)$, but not different $(P>0.05)$ from higher rates $(74 \%)$.

\subsection{Influence on microbial diversity}

Microbial diversity (bacterial and fungal) was assessed with the Shannon index. The number of studies reporting bacterial diversity was large enough for a strong metaanalysis, but the number of studies reporting changes in

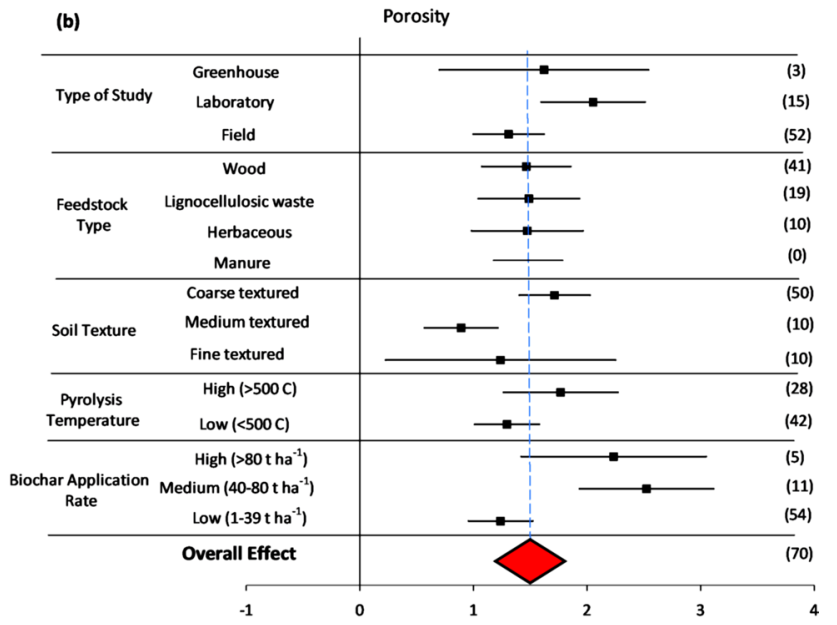

effects for a given group and bars represent $95 \%$ confidence interval for specific categories; blue tick lines show overall effects (grand mean) and numbers at right represent total numbers of replicates (n) from the combined studies

fungal diversity was limited. Changes in microbial diversity (bacterial and fungal) in response to biochar additions grouped by different categories (type of study, feedstock type, soil texture, pyrolysis temperature, and biochar application) are presented in Fig. 4.

\subsubsection{Bacterial diversity}

Biochar applications significantly $(P<0.0001)$ increased bacterial diversity compared to the control (Fig. 4a) but increased significantly $(P<0.05)$ only in laboratory $(55 \%)$ and field (38\%) studies. Biochar from herbaceous feedstocks significantly $(P<0.05)$ increased bacterial diversity, while diversity responses to biochars from wood (11\%), manure (18\%), or lignocellulosic waste (18\%) were not significantly different from the control. Biochar application significantly $(P<0.05)$ increased bacterial diversity in coarse $(24 \%)$ and medium-textured soils (31\%) to a similar extent, but not in fine-textured soils (18\%). Biochars prepared at both high and low pyrolytic temperatures significantly increased $(P<0.05)$ bacterial diversity compared to the control, with the effect being more pronounced with biochar prepared at lower temperatures (35\%). Bacterial diversity was significantly $(P<0.05)$ increased at medium $(25 \%)$ and low application rates $(28 \%)$ with no difference between the medium and low rates.

\subsubsection{Fungal diversity}

Biochar application significantly increased $(P<0.0001)$ fungal diversity compared to the control (Fig. $4 b)$. Fungal diversity with biochar applied was significantly $(P<0.05)$ greater in both greenhouse and field studies but not laboratory 


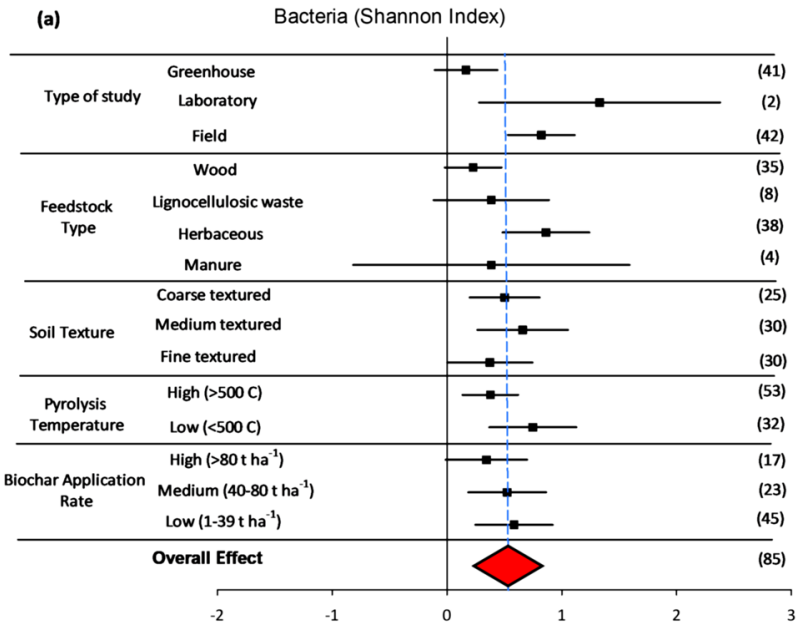

Fig. 4 Forest plots showing the mean changes in microbial diversity due to biochar addition to soil for different categories grouped by type of biochar, feedstock type, soil texture, pyrolysis temperature, and application rate; $\mathbf{a}$ bacterial, and $\mathbf{b}$ fungal. Points show treatment

studies. The increase in fungal diversity was more pronounced in greenhouse studies (43\%). Biochars from lignocellulosic waste and herbaceous feedstocks significantly increased $(P<0.05)$ fungal diversity $(63 \%$ and $25 \%$, respectively) compared to the control, while there was no effect from wood biochar. For biochar from animal waste, there was insufficient information to assess fungal biodiversity. In contrast to changes in bacterial diversity, fungal diversity was significantly increased $(P<0.05)$ in fine-textured soils $(26 \%)$, but not in medium or coarse-textured soils. Biochars prepared under both high and low pyrolytic temperatures significantly $(P<0.05)$ increased fungal diversity compared to the control, with effects being more pronounced with biochar prepared at lower temperatures (43\%). Fungal diversity was significantly increased $(P<0.05)$ compared to the control, but only at lower application rates where it was increased by $43 \%$.

\subsection{Influence on crop productivity}

Studies included in the meta-analysis reported yields for various crops including wheat, maize, canola, barley, rice, sorghum, tomato, groundnut, faba bean, turnip, and peanuts. Biochar applications significantly $(P<0.0001)$ increased crop yield compared to the control (Fig. 5). Crop yields were significantly greater $(P<0.05)$ than the control in both greenhouse (34\%) and field (30\%) studies, but not in laboratory studies. The magnitudes of increases in crop yield were statistically similar for both greenhouse and field studies. Among feedstock type, significant $(P<0.05)$ increases in crop yield were reported from biochars prepared from lignocellulosic waste (35\%) and herbaceous (53\%) feedstocks,

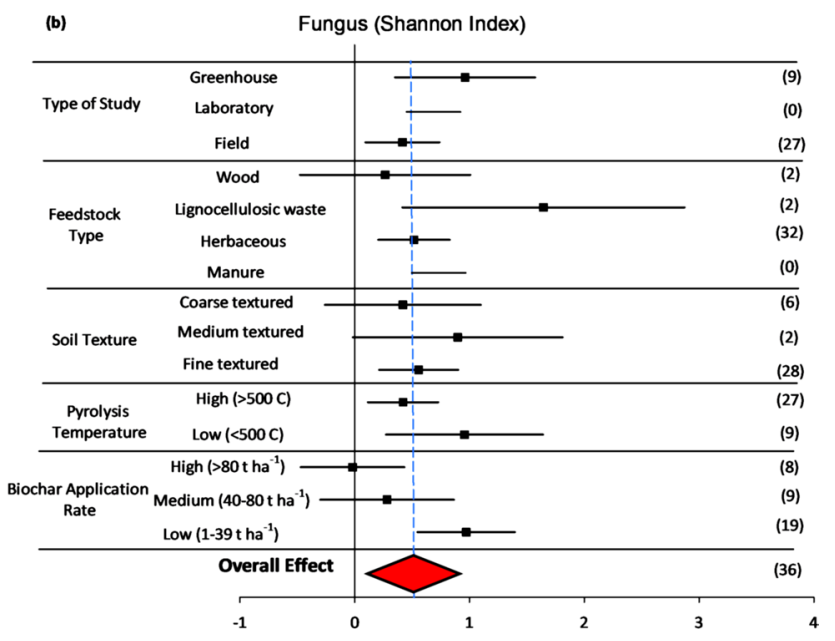

effects for a given group and bars represent $95 \%$ confidence interval for specific categories; blue tick line shows overall effects (grand mean) and numbers at right represent total numbers of replicates (n) from the combined studies

while there was no significant effect on yields for wood biochar $(17 \%)$. Biochar application significantly $(P<0.05)$ increased crop yields in fine (40\%) and coarse-textured soils (57\%) while there was no significant increase in mediumtextured soils (9\%). Biochar prepared under low pyrolytic temperatures significantly $(P<0.05)$ increased crop yields (43\%) compared to the control, but not for high pyrolytic temperatures. Increases in crop yields were significant $(P<0.05)$ at low $(30 \%)$ and medium rates $(40 \%)$ of application, while there was no study that reported crop yield at high rates of biochar application.

\subsection{Correlation and regression analysis}

The effects of biochar applications on all soil properties except soil $\mathrm{pH}, \mathrm{EC}$ and fungal diversity were significantly correlated with the effect of biochar application on soil OC (Table 1). The effect of biochar applications on soil EC was not correlated with other soil properties. Decreases in bulk density due to biochar applications were significantly correlated with increases in soil porosity $(P<0.0001$, $\left.\mathrm{R}^{2}=0.5225\right)$, soil CEC $\left(P<0.05, \mathrm{R}^{2}=0.2837\right)$, soil OC $\left(P<0.01, \mathrm{R}^{2}=0.1283\right)$, and fungal diversity $(P<0.01$, $\mathrm{R}^{2}=0.4232$ ). Increase in bacterial diversity related to biochar applications was only correlated with soil OC $(P<0.05$, $\mathrm{R}^{2}=0.1782$ ).

Increases in crop productivity as a result of biochar applications were positively correlated with the effects of biochar applications on; soil $\mathrm{pH}\left(P=0.039, \mathrm{R}^{2}=0.0715\right.$, Fig. 6a), soil EC $\left(P<0.001, \mathrm{R}^{2}=0.364\right.$, Fig. $\left.6 \mathrm{c}\right)$, and soil porosity $\left(P<0.001, \mathrm{R}^{2}=0.292\right.$, Fig. $\left.6 \mathrm{f}\right)$. These results were 


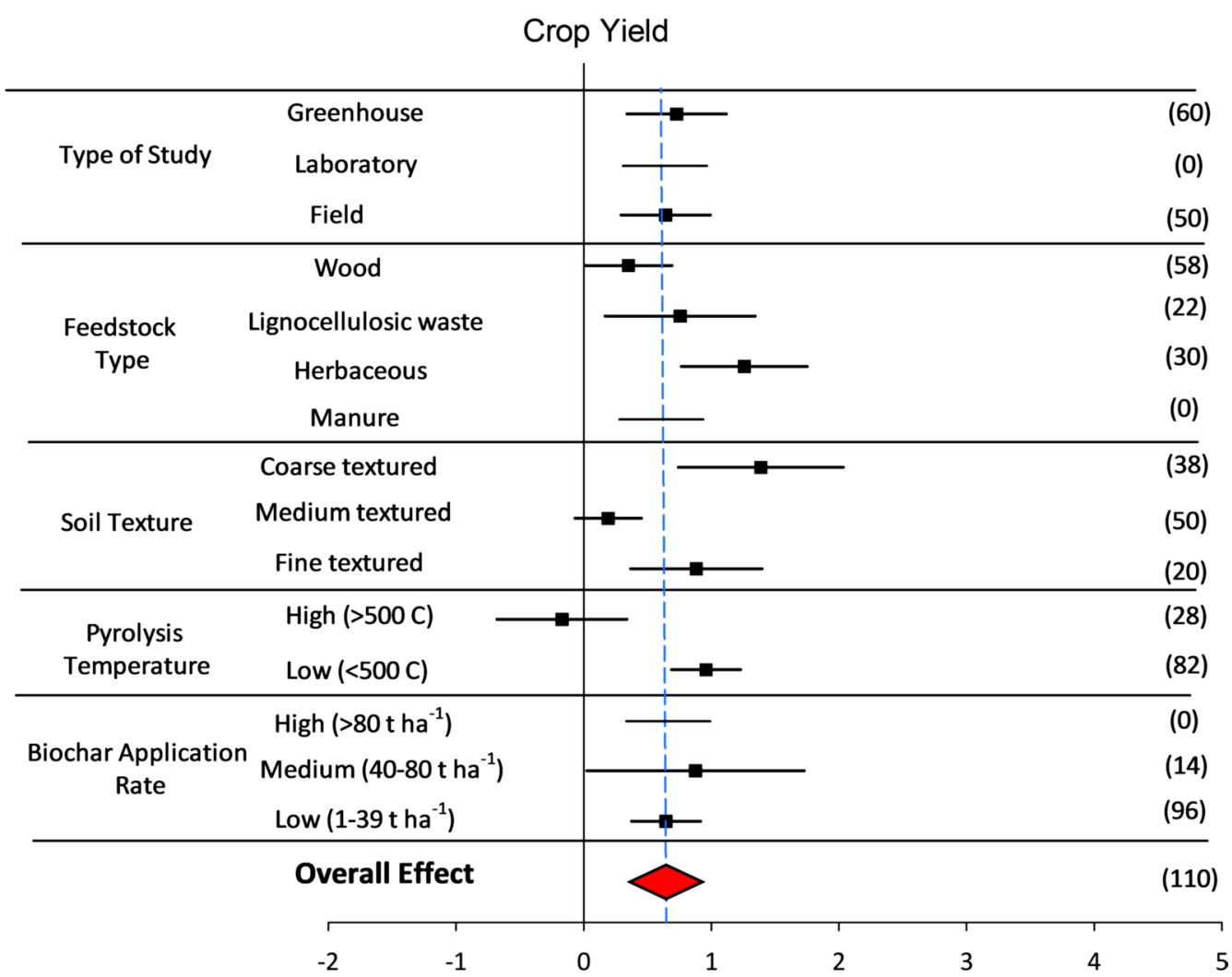

Fig. 5 Forest plots showing the mean changes in crop yield due to biochar addition to soil for different categories grouped by type of biochar, feedstock type, soil texture, pyrolysis temperature, and application rate. Points show treatment effects for a given group and bars represent 95\% confidence interval for specific category; blue tick lines show overall effects (grand mean) and numbers at right represent the total number of replicates (n) from the combined studies

Table 1 Correlation between effect sizes of biochar on chemical and physical properties of soils, and microbial diversity

\begin{tabular}{|c|c|c|c|c|c|c|c|c|}
\hline & Soil pH & Soil EC & Soil CEC & Soil OC & $\begin{array}{l}\text { Soil bulk } \\
\text { density }\end{array}$ & Soil porosity & $\begin{array}{l}\text { Bacterial } \\
\text { diversity }\end{array}$ & Fungal diversity \\
\hline Soil pH & 1.000 & & & & & & & \\
\hline Soil EC & $\begin{array}{l}\mathrm{R}^{2}=0.0022 \\
\mathrm{P}>0.05\end{array}$ & 1.000 & & & & & & \\
\hline Soil CEC & $\begin{array}{l}\mathrm{R}^{2}=0.0170 \\
\mathrm{P}>0.05\end{array}$ & $\begin{array}{l}R^{2}=0.0637 \\
P>0.05\end{array}$ & 1.000 & & & & & \\
\hline Soil OC & $\begin{array}{l}\mathrm{R}^{2}=0.0261 \\
\mathrm{P}>0.05\end{array}$ & $\begin{array}{l}\mathrm{R}^{2}=0.0195 \\
\mathrm{P}>0.05\end{array}$ & $\begin{array}{l}R^{2}=0.1068 \\
P<0.05\end{array}$ & 1.000 & & & & \\
\hline $\begin{array}{l}\text { Soil bulk Den- } \\
\text { sity }\end{array}$ & $\begin{array}{l}R^{2}=0.2234 \\
P<0.0001\end{array}$ & $\begin{array}{l}\mathrm{R}^{2}=0.0026 \\
\mathrm{P}>0.05\end{array}$ & $\begin{array}{l}R^{2}=0.2837 \\
P<0.05\end{array}$ & $\begin{array}{l}R^{2}=0.1283 \\
P<0.01\end{array}$ & 1.000 & & & \\
\hline Porosity & $\begin{array}{l}R^{2}=0.2828 \\
P<0.0001\end{array}$ & $\begin{array}{l}\mathrm{R}^{2}=0.0165 \\
\mathrm{P}>0.05\end{array}$ & $\begin{array}{l}\mathrm{R}^{2}=0.1405 \\
\mathrm{P}>0.05\end{array}$ & $\begin{array}{l}R^{2}=0.1396 \\
P<0.01\end{array}$ & $\begin{array}{l}R^{2}=0.5225 \\
P<0.0001\end{array}$ & 1.000 & & \\
\hline $\begin{array}{l}\text { Bacterial diver- } \\
\text { sity }\end{array}$ & $\begin{array}{l}\mathrm{R}^{2}=0.00003 \\
\mathrm{P}>0.05\end{array}$ & $\begin{array}{l}\mathrm{R}^{2}=0.1443 \\
\mathrm{P}>0.05\end{array}$ & $\begin{array}{l}\mathrm{R}^{2}=0.0118 \\
\mathrm{P}>0.05\end{array}$ & $\begin{array}{l}R^{2}=0.1782 \\
P<0.05\end{array}$ & $\begin{array}{l}R^{2}=0.1757 \\
P>0.05\end{array}$ & NA & 1.000 & \\
\hline Fungal diversity & $\begin{array}{l}\mathrm{R}^{2}=0.0072 \\
\mathrm{P}>0.05\end{array}$ & NA & NA & $\begin{array}{l}\mathrm{R}^{2}=0.1039 \\
\mathrm{P}>0.05\end{array}$ & $\begin{array}{l}R^{2}=0.4232 \\
P<0.01\end{array}$ & NA & $\begin{array}{l}\mathrm{R}^{2}=0.0300 \\
\mathrm{P}>0.05\end{array}$ & 1.000 \\
\hline
\end{tabular}

Bold represents the statistically significant correlation

consistent with the overall trends identified by the above meta-analysis. The effects of biochar applications on crop productivity were positively correlated with effect sizes of biochar application on soil OC (Fig. 6b) and CEC (Fig. 6c) but were not significant $(P>0.05)$. The effects of biochar applications on bulk density were negatively $(P<0.007$, 

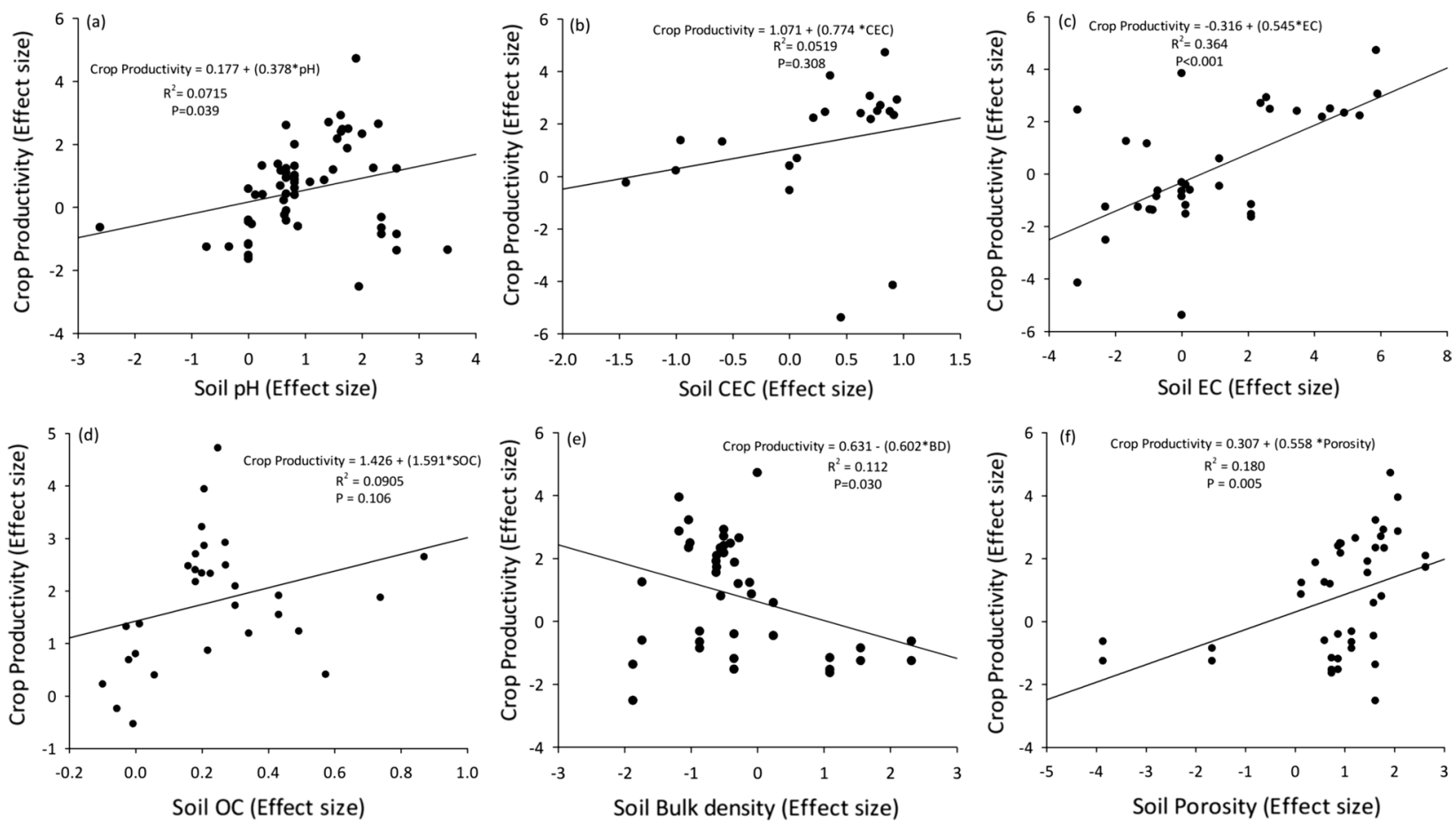

Fig. 6 Regression analyses of relationship between effect sizes of biochar additions on soil chemical and physical properties, and crop productivity; a pH; b CEC: cation exchange capacity; c EC: electrical

conductivity; d OC: organic carbon; e bulk density; f porosity. Cases with $P$ values $<0.05$ indicate significant relationships between biochar property and crop productivity

$\mathrm{R}^{2}=0.166$, Fig. 6e) related to the effect of biochar application on crop productivity.

Regression analyses examined the relationship between effect sizes on crop productivity in response to increasing rates of biochar application, differentiated by biochar prepared from different feedstocks (Fig. 7a) and applications to different types of soils (Fig. 7b). Among feedstocks, biochar prepared from herbaceous feedstocks resulted in increases in effect sizes on crop productivity with increases in biochar application rates. However, biochars derived from wood and lignocellulosic waste had greater effect sizes on crop productivity at lower rates of application compared to higher rates (Fig. 7a). Similarly, among soil types, biochar applied to medium-textured soils resulted in increased effect sizes on crop productivity with increased rates of biochar application (Fig. 7b). However, the opposite trend was observed for crop production with increases in application rates to coarse and fine-textured soils.

\section{Discussion}

\subsection{Experiment type and biochar response}

In general, the effects of biochar applications on most soil properties were greater for laboratory and greenhouse

experiments than for field experiments. For field studies, biochar would undergo weathering and degradation (Anderson et al. 2014). Further, biochar would be diluted due to mixing into the soil profile by tillage (Schlatter et al. 2018), which would lead to decreased effects of biochar on soil properties ( $\mathrm{Li}$ et al. 2020). In contrast, the more-protected conditions in greenhouse or laboratory studies provide slower, or less change, in biochar properties, thereby providing greater effects on soil properties. However, laboratory or greenhouse studies are not representative of conditions found under field conditions (Blanco-Canqui 2017). Our result suggests caution should be exercised when comparing results between studies applied at field scales to those applied in laboratories, or when extending laboratory-based results to field-based settings.

\subsection{Biochar application and soil chemical properties}

Biochar amendments significantly improved chemical properties of soils, with the exception of soil EC. Several studies documented an increase in soil $\mathrm{pH}$ as a result of biochar applications (Sohi et al. 2010; Syuhada et al. 2016; Verheijen et al. 2010), and results from the meta-analysis were consistent with these studies. Significant $(P<0.05)$ increases in soil $\mathrm{pH}$ due to biochar applications occurred under all grouping 

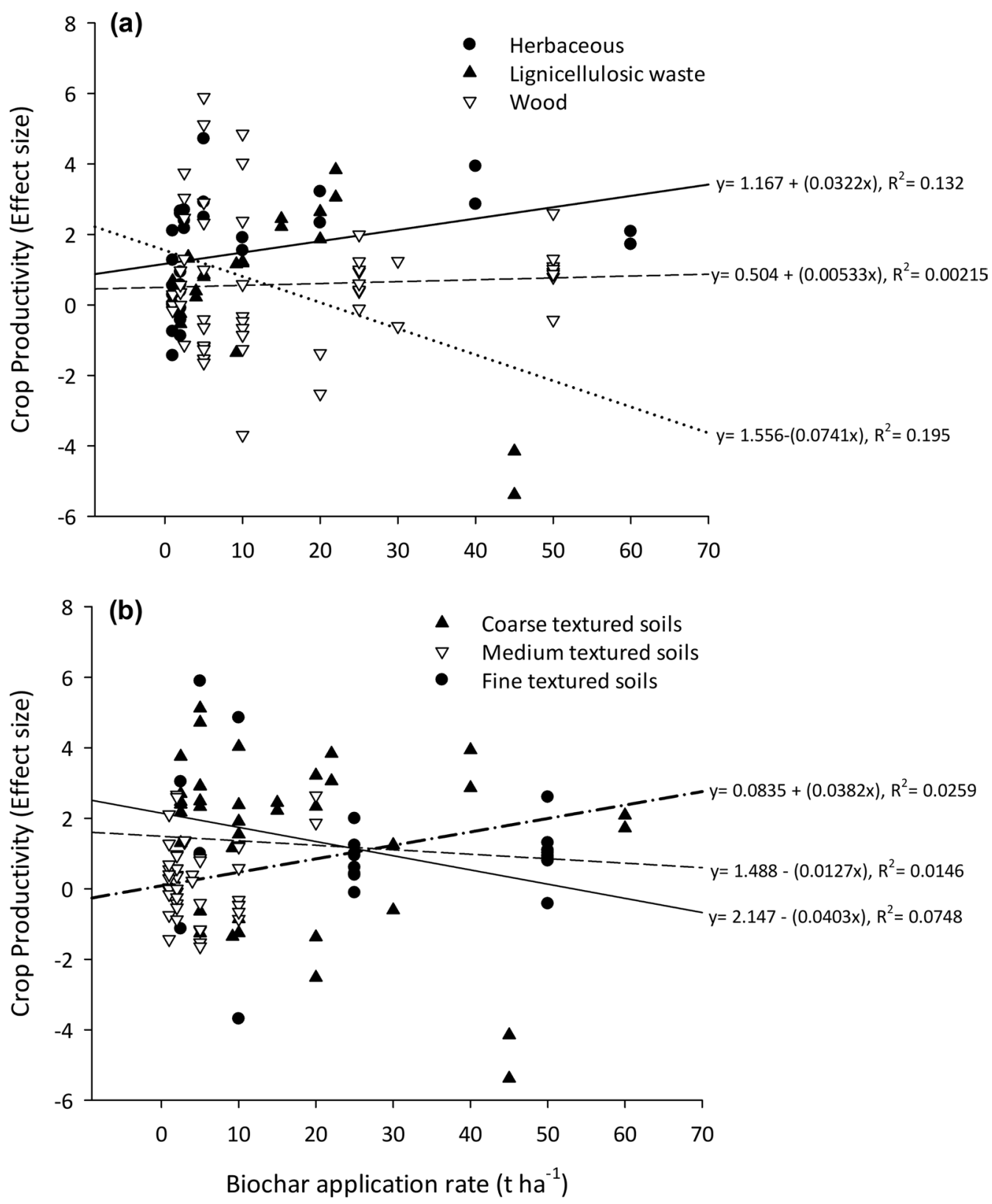

Fig. 7 Regression analysis of changes in crop productivity with application rates of biochar; $\mathbf{a}$ effects of biochar feedstocks; and $\mathbf{b}$ effects of soil types

categories. One possible reason for this increase in soil $\mathrm{pH}$ could be reductions in exchangeable aluminum ( $\mathrm{Al})$ as a result of biochar application (Syuhada et al. 2016). Biochar application could lower $\mathrm{Al}$ concentrations in soils by: (i) adsorbing exchangeable $\mathrm{Al}$ on negatively charged biochar particles, or (ii) reducing the activity of $\mathrm{Al}$ in soil solutions through chelation by soluble organic compounds from biochar (Hue et al. 1986; Butnan et al. 2015).

Another possible explanation for increases in soil $\mathrm{pH}$ due to biochar application is that basic cations $\left(\mathrm{Ca}^{2+}\right.$,
$\mathrm{Mg}^{2+}$ and $\mathrm{K}^{+}$) in biochar could be altered to alkaline substances (such as oxides, hydroxides, and carbonates) during pyrolysis, and the dissolution of these substances causes biochar to act as a liming substance. However, feedstock type and pyrolysis temperatures play important roles in determining the effect of biochar on soil $\mathrm{pH}$. Biochar prepared at higher pyrolytic temperatures have a more alkaline pH (Cantrell et al. 2012; Yuan et al. 2011), and higher carbonate contents compared to biochars prepared at lower pyrolytic temperatures (Wang et al. 2013). 
Results from the current meta-analysis did not show increases in soil EC in response to biochar applications (Fig. 2b). However, results from previous studies reported biochar applications significantly increased soil EC when high amounts of ash were present. Biochars derived from herbaceous feedstocks have greater ash contents than woodderived biochars, which explains their greater effect sizes on soil EC (Kloss et al. 2012). Similarly, Brewer et al. (2011) reported biochars produced from switchgrass and corn stover, under similar temperatures, had higher ash contents than biochars produced from woody materials like red oak and wood wastes. In addition to feedstock, pyrolysis temperatures used for biochar preparation can also impact biochar characteristics and their effect sizes on soil properties. Biochar prepared at temperatures of 400 to $550{ }^{\circ} \mathrm{C}$ has higher $\mathrm{EC}$, thereby increasing soil EC to a greater extent (Singh et al. 2010). In the current study, these temperatures were characterized as low pyrolytic temperatures, and similar results were observed, with greater effect sizes for applications of biochars prepared with lower pyrolysis temperatures (Fig. 2b).

Pyrolyzed organic residues in biochars provide oxygencontaining functional groups (carboxyl, carbonyl, and hydroxyl), that can enhance CEC in soils (Uchimiya et al. 2010). However, this effect can be altered by both feedstock type and pyrolysis temperatures. In concurrence with the current meta-analysis, several studies reported biochars derived from herbaceous materials had greater CEC than biochars derived from wood or other wastes (Kloss et al. 2012; Wang et al. 2013), thereby having greater effect sizes on soil CEC. However, mixed results have been reported for the effect of temperatures used for biochar preparation on CEC. Lehmann (2007) reported an increase in biochar CEC with increasing pyrolytic temperature, which would result in increased soil CEC. In contrast, Singh et al. (2010) and Kloss et al. (2012) reported lower biochar CEC with higher pyrolytic temperatures, resulting into lower soil CEC. However, responses also depend on the rate of application. This decrease in biochar CEC can be attributed to the loss of several acidic functional groups during pyrolysis at higher temperatures (Guo and Rockstraw 2007). Such mixed results could be related to interactions among factors, such as residence time during pyrolysis and feedstocks type (Lu and Zong 2018).

One chemical property of soils that was affected by biochar applications was OC. The response can be attributed to the recalcitrant nature of carbon present in biochars (Abrishamkesh et al. 2015). Biochar contains highly stable forms of carbon when prepared at higher temperatures (above 400-500 ${ }^{\circ} \mathrm{C}$ ). Such temperatures cause aromatization and loss of functional groups and the formation of larger complexes of aromatic rings, which are resistant to both biotic and abiotic degradation (Zimmerman and Gao 2013).
Therefore, adding biochar that contains highly stabile carbon to soils results in increased amounts of soil OC. However, the amount of carbon contributed by biochar applications and its stability in soils depend on several factors, including feedstock type, pyrolysis temperature and rate of application. Biochars derived from herbaceous biomass have higher carbon contents (36.7 and $60.0 \mathrm{wt} \%$ ) than wood-derived biochars (34.9 and 45.9 wt\%) (Wang et al. 2013). However, results from the current meta-analysis, did not find significant differences for effect sizes on soil OC among biochars prepared from different feedstocks (Fig. 1d).

In the current meta-analysis, effect sizes for biochars prepared at different pyrolytic temperatures on soil OC were not different, which was consistent with the results of Wang et al. (2013), where raising pyrolytic temperatures did not increase carbon content in biochars. However, Kloss et al. (2012) reported the carbon content of biochars increased significantly with increasing pyrolytic temperatures and might impact soil OC. The difference in these results could be related to complex interactions between feedstock and the method of pyrolysis applied in the different studies. However, soil OC is reported to increase linearly with increased amounts of biochar applied.

\subsection{Biochar application and soil physical properties}

Biochar application significantly reduced bulk density and increased porosity of soils (Fig. 3). Adding porous materials like biochar reduces bulk densities and increases porosities of soils, since porosity and bulk density are inversely related (Kakaire et al. 2015). However, the effect sizes of different biochars on these two soil properties may vary depending on the application rate, soil texture, and the physical properties of biochar (which depends on feedstock types and pyrolysis temperatures). Increasing rates of biochar application reduces bulk density of soils. Githinji (2014) described reductions in bulk density in response to the application rate as: Bulk density $=-0.240 *$ (\% biochar $)+1.576$. Results from the current meta-analysis are consistent with this relationship (Fig. 3a).

Biochars can differ in their physical properties, such as surface area and porosity, due to feedstock type and pyrolytic conditions, which affects bulk density of soils. Additionally, interactions among feedstock type and pyrolysis conditions applied for biochar preparation can affect physical properties of soils. Lu and Zong (2018) reported a decrease in porosity and surface area of rice straw based-biochar with increasing pyrolysis temperatures. In contrast, both parameters increased in biochar produced from maize straw when prepared using higher temperatures.

Another important factor determining the decrease in bulk density of soils with biochar application is soil texture. Blanco-Canqui (2017) reported bulk density decreased to a 
greater extent when biochar was applied to coarse-textured soils compared to fine-textured soils. One possible reason for this response could be differences in size and density between biochar particles and (larger) sand versus (smaller) clay particles.

Given the inverse relationship between bulk density and porosity of soils, biochar applications result in significant increases in soil porosity (Fig. 3b). Biochar increased soil porosity due to its highly porous nature. Biochar contains longitudinal pores of sizes that range from micro- to macropores (Tomczyk et al. 2020), and the porosity of biochar can be affected by different factors, including feedstock type, pyrolysis temperature, and length of time pyrolysis applied (Leng et al. 2020). Among feedstocks, biochar containing higher amounts of lignin possesses greater porosity since pore structure under pyrolysis is preserved due to the stability of lignin (Tomczyk et al. 2020). In contrast, feedstocks with higher ash contents have lower porosity since pore spaces are blocked by ash. Therefore, wood-based biochar has a greater effect on soil porosity compared to biochar derived from manures, which have greater ash contents (Leng et al. 2020). However, the current meta-analysis found no significant difference between effects sizes of biochars derived from different feedstocks related to soil porosity.

Among pyrolytic temperatures, biochar prepared at higher temperatures are reported to have greater pore space compared to biochars prepared at lower temperatures (Leng et al. 2020). The driver of this response is that volatile constituents in biomass do not devolatilize completely at lower temperatures and may either block some pores or hinder the formation of new pores during pyrolysis (Pallarés et al. 2018). Therefore, biochars prepared at higher temperatures generated a greater effect on soil porosity (Fig. 3b). The effect of biochar application on soil porosity was expected to increase with increasing amounts of biochar applied, but the effect size on soil porosity decreased at higher application rates. This response during the current meta-analysis can be attributed to the low number of datasets $(n=5)$ reporting higher rates of application that were included in the analysis.

\subsection{Biochar application and soil microbial diversity}

In general, biochar application significantly increased bacterial and fungal diversity. This improvement can be attributed to the amounts of labile carbon, and micro- or macro-nutrients, provided by biochar that are available to the microbial communities in soils (Sohi et al. 2010; Xu et al. 2016). Additionally, the increase in soil porosity with biochar applications protects some microbial organisms from predation, thereby increasing microbial biomass and diversity (Palansooriya et al. 2019; Warnock et al. 2007). The results from the current meta-analysis supported this hypothesis, with greater effect sizes of biochar applications on bacterial diversity in medium and coarse-textured soils, compared to fine-textured soils. Other studies also reported increasing bacterial diversity with biochar application (Blanco-Canqui 2017; Lehmann 2007; Palansooriya et al. 2019).

In comparison, fungal diversity did not improve, as the Shannon index for fungal diversity did not differ among soil textures. Fungal communities are usually more stable than bacterial communities and less mobile due to fungal hyphae attached to soil particles. Both bacterial and fungal diversity decreased with application of biochar prepared at higher pyrolytic temperatures (Fig. 4a and b). These results are consistent with a previous meta-analysis by Li et al. (2020). The possible explanation for this effect could be the availability of macro- and micro-pores. Biochar prepared using high pyrolytic temperatures contain a high percentage of micropores ( $<2 \mathrm{~nm}$ of pore diameter) that can only be colonized by a small portion of microbial communities (Quilliam et al. 2013), resulting in a decrease of overall microbial diversity. In comparison, biochar produced at lower pyrolytic temperatures contains volatile compounds that are unstable and bioavailable, which can enhance bacterial and fungal diversity (Ameloot et al. 2013).

The decrease in bacterial and fungal diversity with increases in amounts of biochar applied was consistent with the results of a meta-analysis by Li et al. (2020). The negative effects of high rates of biochar application on microbial diversity may be caused by: (i) disruption of the microenvironment for microbial growth due to high application rates (Masiello et al. 2013; Mccormack et al. 2013), which triggers selection within microbial populations, resulting in decreased microbial diversity (Hartmann et al. 2009); (ii) the introduction of toxic components(Muhammad et al. 2018); or (iii) higher carbon:nitrogen biochars limit carbon metabolism by microbial communities, (Ameloot et al. 2013; Liu et al. 2020).

\subsection{Crop productivity}

The influence of biochar applications on crop productivity depends on interactions among several factors. Among these factors are feedstock type, pyrolysis temperature, application rate, and soil texture. Biochar produced at pyrolysis temperatures of $400-500{ }^{\circ} \mathrm{C}$ was most effective in increasing crop productivity, while biochar produced under high temperatures (especially $>600{ }^{\circ} \mathrm{C}$ ) decreased crop productivity ( $\mathrm{Li}$ et al. 2019). This is consistent with results from the current meta-analysis, as responses of crop yields to applications of biochar prepared at high temperatures were not different from the control (Fig. 5). Biochar produced at high pyrolytic temperatures held water and dissolved minerals tightly, resulting in less water and minerals available for plant growth (Li et al. 2019). Greater impacts of biochar application on crop productivity were observed in coarse 
textured soils, as noted in effect sizes of biochar application on soil properties. Among feedstocks, crop productivity increased in response to herbaceous biochar, compared to wood-based biochar. Herbaceous biochars have greater amounts of nutrients compared to wood derived biochar (Latini et al. 2019), and wood-derived biochars are higher in lignin content, which can immobilize nutrients (Kloss et al. 2012).

Increases in crop productivity were correlated with effect sizes of biochar application on the physical properties (bulk density and porosity) of soil. In contrast, only increases in soil EC were correlated to greater crop productivity among the chemical properties of soil. A possible explanation for the correlation with physical properties was the positive impact of decreased bulk density and increased soil porosity on improving water and nutrient status, and improved soil aeration (Page et al. 2020; Ontl and Schulte 2012). The pore volume of biochar consists of a range of size classes relevant to storage of plant available water. Therefore, increases in soil porosity have positive impacts on crop productivity by increasing amount of water that is plant available, and providing better conditions for root growth (Lu and Zong 2018). The correlation between crop productivity and decreased bulk density could be related to the facilitation of root growth by the decrease in bulk density, and movement of air and water through soil, which can have positive impacts on crop growth (USDA 2019).

\section{Research gaps and future needs}

This meta-analysis presented gaps in the literature that need to be addressed. Some specific research needs include:

- Most studies evaluating the effect of biochar on soil properties were conducted for durations of less than 2 years. It is important to conduct longer-term studies since biochar properties can change with aging, as might its impacts on soil properties. Longer-duration studies will provide an increased understanding of the effects of biochar over time and help define timings for reapplication of biochar.

- Most studies were conducted on acidic soils and resulted in increased soil $\mathrm{pH}$ due to the alkaline nature of biochar. Few studies were conducted on more-alkaline soils. Therefore, there is a need to evaluate the effects of biochar applications on soil properties of neutral or higher $\mathrm{pH}$ soils.

- There were few studies evaluating changes in fungal diversity in response to biochar application, compared to bacterial diversity. As fungal biomass and diversity are important factors governing various soil mechanisms (e.g., decomposition of organic matter, emission of greenhouse gasses), it is important to evaluate changes in fungal diversity and biomass in response to biochar applications to different soils.

- Studies conducted under field conditions are less common than those undertaken in the smaller scales of laboratory or greenhouse studies. As responses in such studies differ from field studies, due to variances in soil properties, weather, and environmental conditions, it is important to conduct more field trials.

- Most studies examine bio-physical characteristics or crop productivity. Studies on cost-benefit analyses and understanding the barriers to using biochar are required.

- Studies should consider impacts of biochar applications as soil amendments that include bioenergy production, offsetting emissions of greenhouse gasses, carbon sequestration, and agronomic impacts on crop production, in addition to how biochar effects soil properties.

- The interactions of biochar feedstock, method, and temperature conditions of preparing biochar and their performance of different soil texture need to be better understood to determine site-specific biochar recommendations.

- The full lifecycle economic analysis and return on investments of biochar application need critical analysis under different biophysical and socio-economic conditions.

\section{Conclusions}

Biochar has long been seen as a potential amendment to improve soils and enhance agricultural production. This meta-analysis of the available literature assessed the current state of knowledge on how biochar applications can affect soil physical and chemical properties, microbial diversity, and crop production. Biochar additions had a variety of effects on soil properties and microbes, and crop production, in response to feedstock type, pyrolysis temperatures, soil texture, and amounts applied. All chemical properties of soils except EC improved, with larger increases occurring in response to higher application rates, and greater responses in coarse and fine-textured soils. Improvements also occurred among the correlated responses of bulk density and porosity, with larger responses occurring in coarsetextured soils, and to biochars prepared at higher pyrolytic temperatures. In general, both bacterial and fungal diversity increased with biochar application, though diversity declined at higher rates of application. As with soil properties, improvement in microbial diversity was dependent on soil type and affected by pyrolytic temperatures applied to biochars. Increases in crop production were also dependent on soil type, pyrolysis temperatures and rates of application, largely due to the effects of these factors on physical properties of soils. Biochar prepared at high temperatures $\left(>500{ }^{\circ} \mathrm{C}\right.$ ) helped to increase soil CEC and porosity but had 
negative impacts on crop productivity, thereby preparation of biochars at temperatures $<500{ }^{\circ} \mathrm{C}$ can be recommended. Use of herbaceous feedstock for biochar preparation can be recommended due to positive effects on crop productivity, microbial abundance, and soil properties except $\mathrm{pH}$. The combined responses of soil properties, soil microbes, and crop productivity indicate the effects of biochar applications on agroecosystems will be neither uniform nor common, with responses dependent on the attributes of applied biochars and soil types receiving treatments. Differences in the recorded effects of field-based studies, compared to studies in more-controlled environments, indicate results from laboratory or greenhouse studies should be applied to field settings with caution. Longer-term field trials are required to define how biochar affects soil properties under the varied conditions and environments affecting agroecosystems, and the economic performance of biochar applications.

Supplementary Information The online version contains supplementary material available at https://doi.org/10.1007/s42773-022-00138-1.

Authors' contributions This meta-analysis was done by HS under the supervision of BKN and VPP. Studies were selected, and data was analyzed by HS. This report was drafted by HS, and reviewed by BKN, CWR, VPP.

Funding This research was partly supported by a National Institute of Food and Agriculture, United States Department of Agriculture research award (Number 2019-68012-29888), the Sustainable Intensification Innovation Lab funded by the United States Agency for International Development (Grant Number AID-OAA-L-14-00006), and funds allocated to the USDA-ARS project 3070-21610-003-00D. The contents of this publication are the sole responsibility of authors and do not reflect the views of funding agencies and representing organizations. Contribution No. 21-310-J from the Kansas Agricultural Experiment Station. The US Department of Agriculture (USDA) is an equal opportunity employer and provider of services in all its programs and activities. Mention of trademarks, proprietary products, or vendors does not constitute guarantee or warranty of products and does not imply its approval to the exclusion of other products that may be suitable.

Availability of data and materials The datasets generated during and/or analyzed during the current study are available from the corresponding author on reasonable request.

Code availability The code used to analyze dataset for the current study are available from the corresponding author on reasonable request.

\section{Declarations}

Ethics approval and consent to participate I ensure that all the authors mentioned in the manuscript have agreed for authorship, read and approved the manuscript, and given consent for submission and subsequent publication of the manuscript. Not applicable.

Consent for publication Not applicable.

Competing interests The authors declare that they have no known or perceived competing financial interests or personal relationships that would influence the work reported in this paper.
Open Access This article is licensed under a Creative Commons Attribution 4.0 International License, which permits use, sharing, adaptation, distribution and reproduction in any medium or format, as long as you give appropriate credit to the original author(s) and the source, provide a link to the Creative Commons licence, and indicate if changes were made. The images or other third party material in this article are included in the article's Creative Commons licence, unless indicated otherwise in a credit line to the material. If material is not included in the article's Creative Commons licence and your intended use is not permitted by statutory regulation or exceeds the permitted use, you will need to obtain permission directly from the copyright holder. To view a copy of this licence, visit http://creativecommons.org/licenses/by/4.0/.

\section{References}

Abewa A, Yitaferu B, Selassie YG, Amare T (2014) The role of biochar on acid soil reclamation and yield of Teff (Eragrostis tef [Zucc] Trotter) in Northwestern Ethiopia. J Agric Sci 6(1):1. https://doi. org/10.5539/jas.v6n1p1

Abrishamkesh S, Gorji M, Asadi H, Bagheri-Marandi GH, Pourbabaee AA (2015) Effects of rice husk biochar application on the properties of alkaline soil and lentil growth. Plant Soil Environ 61(11):475-482. https://doi.org/10.17221/117/2015-PSE

Ali K, Munsif F, Zubair M, Hussain Z, Shahid M, Din IU, Khan N (2011) Management of organic and inorganic nitrogen for different maize varieties. Sarhad J Agric 27(4):525-529

Ameloot N, De Neve S, Jegajeevagan K, Yildiz G, Buchan D, Funkuin YN, Prins W, Bouckaert L, Sleutel S (2013) Short-term $\mathrm{CO}_{2}$ and $\mathrm{N}_{2} \mathrm{O}$ emissions and microbial properties of biochar amended sandy loam soils. Soil Biol Biochem 57:401-410. https://doi.org/ 10.1016/j.soilbio.2012.10.025

Anderson CR, Hamonts K, Clough TJ, Condron LM (2014) Biochar does not affect soil $\mathrm{N}$-transformations or microbial community structure under ruminant urine patches but does alter relative proportions of nitrogen cycling bacteria. Agric Ecosyst Environ 191:63-72. https://doi.org/10.1016/j.agee.2014.02.021

Atkinson CJ (2018) How good is the evidence that soil-applied biochar improves water-holding capacity? Soil Use Manage 34(2):177186. https://doi.org/10.1111/sum.12413

Blanco-Canqui H (2017) Biochar and soil physical properties. Soil Sci Soc Am J 81(4):687-711. https://doi.org/10.2136/sssaj2017. 01.0017

Borenstein M, Hedges LV, Higgins JP, Rothstein HR (2011) Introduction to meta-analysis, 2nd edn. Wiley, Chichester

Brewer CE, Unger R, Schmidt-Rohr K, Brown RC (2011) Criteria to select biochars for field studies based on biochar chemical properties. Bioenergy Res 4(4):312-323. https://doi.org/10.1007/ s12155-011-9133-7

Butnan S, Deenik JL, Toomsan B, Antal MJ, Vityakon P (2015) Biochar characteristics and application rates affecting corn growth and properties of soils contrasting in texture and mineralogy. Geoderma 237:105-116

Cantrell KB, Hunt PG, Uchimiya M, Novak JM, Ro KS (2012) Impact of pyrolysis temperature and manure source on physicochemical characteristics of biochar. Bioresour Technol 107:419-428. https://doi.org/10.1016/j.biortech.2011.11.084

Chan KY, Van Zwieten L, Meszaros I, Downie A, Joseph S (2008) Agronomic values of greenwaste biochar as a soil amendment. Soil Res 45(8):629-634. https://doi.org/10.1071/SR07109

Girmay G, Singh BR, Mitiku H, Borresen T, Lal R (2008) Carbon stocks in Ethiopian soils in relation to land use and soil management. Land Degrad Dev 19(4):351-367. https://doi.org/10.1002/ ldr. 844 
Githinji L (2014) Effect of biochar application rate on soil physical and hydraulic properties of a sandy loam. Arch Agron Soil Sci 60(4):457-470. https://doi.org/10.1080/03650340.2013.821698

Guo Y, Rockstraw DA (2007) Activated carbons prepared from rice hull by one-step phosphoric acid activation. Microporous Mesoporous Mater 100(1-3):12-19. https://doi.org/10.1016/j. micromeso.2006.10.006

Hartmann A, Schmid M, Van Tuinen D, Berg G (2009) Plant-driven selection of microbes. Plant Soil 321(1):235-257. https://doi.org/ 10.1007/s11104-008-9814-y

Hedges LV, Olkin I (2014) Statistical methods for meta-analysis. Academic press, Orlando

Hedges LV, Borenstein M, Higgings J, Rothstein H (2005) Comprehensive meta-analysis. Biostat, Englewood

Hue NV, Craddock GR, Adams F (1986) Effect of organic acids on aluminum toxicity in subsoils. Soil Sci Soc Am J 50(1):28-34. https://doi.org/10.2136/sssaj1986.03615995005000010006x

Jones DL, Healey JR (2010) Organic amendments for remediation: putting waste to good use. Elements 6(6):369-374. https://doi. org/10.2113/gselements.6.6.369

Jones DL, Cross P, Withers PJ, DeLuca TH, Robinson DA, Quilliam RS, Harris IM, Chadwick DR, Edwards-Jones G (2013) Nutrient stripping: the global disparity between food security and soil nutrient stocks. J Appl Ecol 50(4):851-862. https://doi.org/10. 1111/1365-2664.12089

Kakaire J, Makokha GL, Mwanjalolo M, Mensah AK, Menya E (2015) Effects of mulching on soil hydro-physical properties in Kibaale Sub-catchment, South Central Uganda. Appl Ecol Environ Res 3(5):127-135. https://doi.org/10.12691/aees-3-5-1

Kloss S, Zehetner F, Dellantonio A, Hamid R, Ottner F, Liedtke V, Schwanninger M, Gerzabek MH, Soja G (2012) Characterization of slow pyrolysis biochars: effects of feedstocks and pyrolysis temperature on biochar properties. J Environ Qual 41(4):990 1000. https://doi.org/10.2134/jeq2011.0070

Laine J (2012) Perspective of the preparation of agrichars using fossil hydrocarbon coke. Renew Sustain Energy Rev 16(8):5597-5602. https://doi.org/10.1016/j.rser.2012.06.009

Lakens D (2013) Calculating and reporting effect sizes to facilitate cumulative science: a practical primer for t-tests and ANOVAs. Front Psychol 4:863. https://doi.org/10.3389/fpsyg.2013.00863

Lal R (2009) Soils and world food security. Soil till Res 102:1-4. https://doi.org/10.1016/j.still.2008.08.001

Lal R (2013) Food security in a changing climate. Ecohydrol Hydrobiol 13(1):8-21. https://doi.org/10.1016/j.ecohyd.2013.03.006

Latini A, Bacci G, Teodoro M, Gattia DM, Bevivino A, Trakal L (2019) The impact of soil-applied biochars from different vegetal feedstocks on durum wheat plant performance and rhizospheric bacterial microbiota in low metal-contaminated soil. Front Microbiol 10:2694. https://doi.org/10.3389/fmicb.2019.02694

Lehmann J, Gaunt J, Rondon M (2006) Bio-char sequestration in terrestrial ecosystems - a review. Mitig Adapt Strateg Glob Chang 11(2):403-427. https://doi.org/10.1007/s11027-005-9006-5

Lehmann J, Kaempf N, Woods WI, Sombroek W, Kern DC, Cunha TJF (2007) Classification of Amazonian dark earths and other ancient anthropic soils. In: Lehmann J, Kern DC, Glaser B, Woods WI (eds) Amazonian dark earths: origin, properties, management. Springer, New York, pp 77-102

Lehmann J, Rillig MC, Thies J, Masiello CA, Hockaday WC, Crowley D (2011) Biochar effects on soil biota-a review. Soil Biol Biochem 43(9):1812-1836. https://doi.org/10.1016/j.soilbio.2011. 04.022

Leng L, Xiong Q, Yang L, Li H, Zhou Y, Zhang W, Jiang S, Li H, Huang H (2020) An overview on engineering the surface area and porosity of biochar. Sci Total Environ. https://doi.org/10.1016/j. scitotenv.2020.144204
Li S, Harris S, Anandhi A, Chen G (2019) Predicting biochar properties and functions based on feedstock and pyrolysis temperature: a review and data syntheses. J Clean Prod 215:890-902. https:// doi.org/10.1016/j.jclepro.2019.01.106

Li X, Wang T, Chang SX, Jiang X, Song Y (2020) Biochar increases soil microbial biomass but has variable effects on microbial diversity: a meta-analysis. Sci Total Environ 749:141593. https://doi. org/10.1016/j.scitotenv.2020.141593

Liu C, Gong X, Dang K, Li J, Yang P, Gao X, Deng X, Feng B (2020) Linkages between nutrient ratio and the microbial community in rhizosphere soil following fertilizer management. Environ Res 184:109261. https://doi.org/10.1016/j.envres.2020.109261

Lu S, Zong Y (2018) Pore structure and environmental serves of biochars derived from different feedstocks and pyrolysis conditions. Environ Sci Pollut Res 25(30):30401-30409. https://doi.org/10. 1007/s11356-018-3018-7

Masiello CA, Chen Y, Gao X, Liu S, Cheng HY, Bennett MR, Rudgers JA, Wagner DS, Zygourakis K, Silberg JJ (2013) Biochar and microbial signaling: production conditions determine effects on microbial communication. Environ Sci Technol 47(20):1149611503. https://doi.org/10.1021/es401458s

McCormack SA, Ostle N, Bardgett RD, Hopkins DW, Vanbergen AJ (2013) Biochar in bioenergy cropping systems: impacts on soil faunal communities and linked ecosystem processes. Glob Chang Biol (bioenergy) 5(2):81-95. https://doi.org/10.1111/gcbb.12046

Muhammad N, Hussain M, Ullah W, Khan TA, Ali S, Akbar A, Aziz R, Rafiq MK, Bachmann RT, Al-Wabel MI, Rizwan M (2018) Biochar for sustainable soil and environment: a comprehensive review. Arab J Geosci 11(23):1-14. https://doi.org/10.1007/ s12517-018-4074-5

Mukherjee A, Zimmerman AR (2013) Organic carbon and nutrient release from a range of laboratory-produced biochars and biochar-soil mixtures. Geoderma 193:122-130. https://doi.org/10. 1016/j.geoderma.2012.10.002

Ontl TA, Schulte LA (2012) Soil carbon storage. Nature Educ Knowl 3:10

Page KL, Dang YP, Dalal RC (2020) The ability of conservation agriculture to conserve soil organic carbon and the subsequent impact on soil physical, chemical, and biological properties and yield. Front Sustain Food Syst. https://doi.org/10.3389/fsufs.2020.00031

Palansooriya KN, Wong JTF, Hashimoto Y, Huang L, Rinklebe J, Chang SX, Bolan N, Wang H, Ok YS (2019) Response of microbial communities to biochar-amended soils: a critical review. Biochar 1(1):3-22. https://doi.org/10.1007/s42773-019-00009-2

Pallarés J, González-Cencerrado A, Arauzo I (2018) Production and characterization of activated carbon from barley straw by physical activation with carbon dioxide and steam. Biomass Bioenerg 115:64-73. https://doi.org/10.1016/j.biombioe.2018.04.015

Quilliam RS, Glanville HC, Wade SC, Jones DL (2013) Life in the 'charosphere' - does biochar in agricultural soil provide a significant habitat for microorganisms? Soil Biol Biochem 65:287-293. https://doi.org/10.1016/j.soilbio.2013.06.004

Quilty JR, Cattle SR (2011) Use and understanding of organic amendments in Australian agriculture: a review. Soil Res 49(1):1-26. https://doi.org/10.1071/SR10059

Razzaghi F, Obour PB, Arthur E (2020) Does biochar improve soil water retention? A Systematic Review and Meta-Analysis. Geoderma 361:114055. https://doi.org/10.1016/j.geoderma.2019. 114055

Rohatgi A. Web plot digitizerhttp://arohatgi.info/WebPlotDigitizer/ (2010-2013)

Schlatter DC, Kahl K, Carlson B, Huggins DR, Paulitz T (2018) Fungal community composition and diversity vary with soil depth and landscape position in a no-till wheat-based cropping system. FEMS Microbiol Ecol 94(7):fiy098. https://doi.org/10.1093/femsec/fiy098 
Singh B, Singh BP, Cowie AL (2010) Characterisation and evaluation of biochars for their application as a soil amendment. Soil Res 48(7):516-525. https://doi.org/10.1071/SR10058

Sohi SP, Krull E, Lopez-Capel E, Bol R (2010) A review of biochar and its use and function in soil. Adv Agron 105:47-82. https:// doi.org/10.1016/S0065-2113(10)05002-9

Soil Texture - Cornell Soil Health Laboratory - Cornell University. https://cpb-us-e1.wpmucdn.com/blogs.cornell.edu/dist/f/5772/ files/2016/12/04_CASH_SH_Series_Texture_Fact_Sheet_ 072717-286kw9f.pdf accessed 12 Mar 2021

Solomon D, Lehmann J, Thies J, Schäfer T, Liang B, Kinyangi J, Neves E, Petersen J, Luizao F, Skjemstad J (2007) Molecular signature and sources of biochemical recalcitrance of organic C in Amazonian Dark Earths. Geochim Cosmochim Acta 71(9):2285-2298. https://doi.org/10.1016/j.gca.2007.02.014

Syuhada AB, Shamshuddin J, Fauziah CI, Rosenani AB, Arifin A (2016) Biochar as soil amendment: impact on chemical properties and corn nutrient uptake in a Podzol. Can J Soil Sci 96(4):400412. https://doi.org/10.1139/cjss-2015-0044

Tomczyk A, Sokołowska Z, Boguta P (2020) Biochar physicochemical properties: pyrolysis temperature and feedstock kind effects. Rev Environ Sci Biotechnol 19(1):191-215. https://doi.org/10.1007/ s11157-020-09523-3

Uchimiya M, Lima IM, Klasson KT, Wartelle LH (2010) Contaminant immobilization and nutrient release by biochar soil amendment: roles of natural organic matter. Chemosphere 80(8):935-940. https://doi.org/10.1016/j.chemosphere.2010.05.020

Ullah S, Liang H, Ali I, Zhao Q, Iqbal A, Wei S, Shah T, Yan B, Jiang L (2020) Biochar coupled with contrasting nitrogen sources mediated changes in carbon and nitrogen pools, microbial and enzymatic activity in paddy soil. J Saudi Chem Soc 24(11):835-849. https://doi.org/10.1016/j.jscs.2020.08.008

USDA (2019) Soil bulk density/moisture/aeration. United States Department of Agriculture, Natural Resource Conservation
Service - Soil Health Guide for Educators. https://www.nrcs. usda.gov/Internet/FSE_DOCUMENTS/nrcs142p2_050936.pdf

Verheijen F, Jeffery S, Bastos AC, Van der Velde M, Diafas I (2010) Biochar application to soils. A critical scientific review of effects on soil properties, processes, and functions. EUR 24099:162

Wang Y, Hu Y, Zhao X, Wang S, Xing G (2013) Comparisons of biochar properties from wood material and crop residues at different temperatures and residence times. Energy Fuels 27(10):5890 5899. https://doi.org/10.1021/ef400972z

Warnock DD, Lehmann J, Kuyper TW, Rillig MC (2007) Mycorrhizal responses to biochar in soil-concepts and mechanisms. Plant Soil 300(1):9-20. https://doi.org/10.1007/s11104-007-9391-5

Woolf D, Amonette JE, Street-Perrott FA, Lehmann J, Joseph S (2010) Sustainable biochar to mitigate global climate change. Nat Commun 1(1):1-9. https://doi.org/10.1038/ncomms1053

Xu N, Tan G, Wang H, Gai X (2016) Effect of biochar additions to soil on nitrogen leaching, microbial biomass and bacterial community structure. Eur J Soil Biol 74:1-8. https://doi.org/10.1016/j.ejsobi. 2016.02.004

Yao Y, Gao B, Zhang M, Inyang M, Zimmerman AR (2012) Effect of biochar amendment on sorption and leaching of nitrate, ammonium, and phosphate in a sandy soil. Chemosphere 89(11):14671471. https://doi.org/10.1016/j.chemosphere.2012.06.002

Yuan JH, Xu RK, Zhang H (2011) The forms of alkalis in the biochar produced from crop residues at different temperatures. Bioresour Technol 102(3):3488-3497. https://doi.org/10.1016/j.biortech. 2010.11.018

Zhu X, Chen B, Zhu L, Xing B (2017) Effects and mechanisms of biochar-microbe interactions in soil improvement and pollution remediation: a review. Environ Pollut 227:98-115

Zimmerman AR, Gao B (2013) The stability of biochar in the environment. In: Ladygina N, Rineau F (eds) Biochar and soil biota. CRC Press, Boca Raton, pp 1-40 